
\title{
Análise estilística do Rola ou enrola?: uma narrativa que se desenrola no programa Eliana (SBT)
}

\section{STYLISTIC ANALYSIS OF ROLA OU ENROLA? (A.K.A. CONVEYOR BELT OF LOVE): A NARRATIVE THAT UNFOLDS IN THE PROGRAM ELIANA (SBT)}

\section{João Paulo Hergesel}

Doutorando em Comunicação na Universidade Anhembi Morumbi, mestre em Comunicação e Cultura e licenciado em Letras pela Universidade de Sorocaba. Líder do Grupo de Estudos em Narrativas Midiáticas Infantis e Juvenis do Programa de Pós-graduação em Comunicação e Cultura da Universidade de Sorocaba e membro do grupo de pesquisa Inovações e Rupturas na Ficção Televisiva Brasileira, da Universidade Anhembi Morumbi em conjunto com o Conselho Nacional de Desenvolvimento Científico e Tecnológico.

E-mail: jp_hergesel@hotmail.com

\section{Rogério Ferraraz}

Doutor em Comunicação e Semiótica pela Pontifícia Universidade Católica de São Paulo.

Mestre em Multimeios pela Universidade Estadual de Campinas. Professor no Programa de Pós-Graduação em Comunicação da Universidade Anhembi Morumbi.

E-mail: rferraraz@anhembi.br

Recebido em 6 de dezembro de 2017. Aprovado em 31 de janeiro de 2018.

\section{Resumo}

Programas de auditório são macronarrativas em que habitam várias diegeses, cada qual com seus enredos e personagens específicos; são os chamados quadros. O dominical Eliana (SBT, 2009-) enquadra-se nesse perfil, abrangendo, dentre tantos microuniversos compostos por (in)finitos recursos expressivos, o semanal Rola ou enrola?. Com a intenção de discutir os efeitos estilísticos responsáveis por manter o interesse do espectador em um quadro de namoro prestes a completar um quadriênio no ar, questionou-se o que há de peculiar, em sentido comunicacional e cultural, no objeto em evidência.

Palavras-chave: Audiovisual. Televisão. Narrativas midiáticas. Estilística. SBT.

\section{Comunicação \& Inovação, PPGCOM/USCS}




\section{Abstract}

TV shows are macronarratives in which inhabit several diegesis, each one with their specific plots and characters; they are called segments. The dominical show Eliana (2009-) fits this profile, comprehending, among a sum of microuniverses made of (in)finite expressive resources, the weekly Rola ou enrola? (known in English as Conveyor Belt of Love).
In order to discuss the stylistic effects responsible for maintaining the viewer's interest in a dating segment about to complete a quadrennium on air, it was questioned what is peculiar, in a cultural and communicational sense, about the object in evidence.

Keywords: Audiovisual. Television. Media narratives. Stylistics. SBT.

\section{Considerações iniciais}

O programa Eliana (SBT, 2009-) conta histórias, mesmo quando o propósito é unicamente entreter o espectador com situações não lineares. Por ser um programa de auditório, é comum que existam quadros formados por narrativas completas, roteirizadas, fechadas e preparadas para exibir uma ocasião real, em uma espécie de perenização do cotidiano brasileiro. No entanto, também é comum que ocorram atrações movidas pela espontaneidade, sem acontecimentos pré-estabelecidos ou diálogos previsíveis, comunicadas de forma aberta, provocando surpresa no público e, supostamente, nos envolvidos diretamente no palco.

Esse modo de conduzir as ações também pode ser enquadrado como narrativa; entretanto, diferentemente das fórmulas prontas, essas são narrativas em processo. A apresentadora, os convidados, a plateia... são todos personagens focalizados por câmeras que ajudam a determinar tempo e espaço, guiados por diretores e produtores que os ajudam a construir seu próprio enredo. As dálias e o teleprompter oferecem as coordenadas, mas é a criatividade dos participantes e seu comportamento em cena que refletirão no nível de atenção dispensado pelo telespectador.

É possível afirmar, portanto, que os programas de auditório são macronarrativas em que habitam várias diegeses, cada qual com seus enredos e personagens específicos. Em Eliana, é comum que os microuniversos se configurem, entre vários outros exemplos, como em registro do dia a dia de celebridades (Eliana visita), pedidos de casamento personalizados (Quer casar comigo?), transformações de moda e estética corporal (Beleza renovada), homenagens a artistas (Rede da fama) e formação de casais de namorados (Rola ou enrola?). 
Na micronarrativa que se processa a cada episódio do Rola ou enrola?, percebe-se a infinidade de recursos expressivos inseridos com a finalidade de manter a atenção do espectador. Praticamente não há momentos neutros, de silêncio; sempre existe alguma fagulha de informação sendo direcionada para os lares por meio do audiovisual. É preciso, pois, compreender como essas artimanhas da linguagem se moldam para manter o interesse do espectador durante sua exibição.

\section{Foco e escopo}

"Programas televisivos são narrativas que refletem e constroem imagens, representações e valores sociais. Constituem também interlocuções complexas, em que estão enredados diferentes atores sociais" (FRANÇA, 2006, p. 10). Estudar esse tipo de narrativa não é somente oferecer uma descrição verbal de um produto audiovisual, mas entender os processos técnicos adotados pela televisão - no caso, brasileira - em sua relação sociocultural com o público que consome esse tipo de programação.

No contexto de programas de namoro (os chamados dating shows), as emissoras nacionais já exibiram formatos distintos, merecedores de pesquisas científicas. Pode-se enumerar como exemplos: Em nome do amor, do SBT (FERNANDES, 2002); Fica comigo, da MTV (SOARES, 2007); Namoro na TV, Xaveco e Namoro na TV e Etc., os três do SBT (GALVÃO; DUCA, 2010); além da discussão a respeito da liquefação dos sentimentos devido a esse gênero, incluindo os produtos Vai dar namoro, da Rede Record; Beija sapo, A fila anda e LUV MTV, os três da MTV; Quer namorar comigo?, Se rolar, rolou e o próprio Rola ou enrola?, os três do SBT (SILVA et al., 2012).

Tendo em mente uma audiência prioritariamente feminina, Silva et al. (2012, p. 3) dissertam que "os programas de namoro possuem um público cativo, tendo em vista a tradição de algumas emissoras manterem em sua grade programação este tipo de produto durante muitos anos". A audiência se mantém fiel a esse formato, ao que parece, devido à manifestação de emoções por meio do audiovisual, isto é, a expressividade dos elementos sensíveis através da linguagem televisiva - fator detectável pela estilística, disciplina que "estuda os fatos expressivos da linguagem organizada de acordo com seu conteúdo emocional, quer dizer, a expressão dos fatos da sensibilidade por meio da linguagem e a ação dos fatos da linguagem sobre a sensibilidade" (BALLY, 1909, p. 16).

\section{Recorte eleito}

Rola ou enrola?, uma das células audiovisuais responsáveis por compor o dominical Eliana (2009-) desde 30 de outubro de 2011 (ELIANA..., 2011), é a versão brasileira de Conveyor belt of love - ou "esteira rolante do amor", em tradução livre e literal. 
Dating show de cunho afetivo produzido pela Endemol e focado na formação de casais que desejam iniciar um relacionamento sério, esse produto, exportado primeiramente para a Polônia e posteriormente aterrissado no Brasil, recebe a seguinte sinopse:

A cada programa, 5 garotas, sempre as mesmas, sentam-se frente a uma esteira rolante que as apresenta um novo homem a cada 60 segundos. Cada rapaz tem apenas um minuto para se apresentar e tentar impressionar as garotas da maneira que preferir: cantando, dançando, recitando uma poesia, etc. Ao final do programa cada garota deve ter escolhido um candidato, nem um a mais, nem a menos. Seus encontros serão filmados e veiculados no site do programa e no episódio seguinte. (ENDEMOL, 2009)

Ao adaptar o produto para quadro de um programa de auditório - consequentemente, com a inserção de uma plateia e uma apresentadora - e colorir o cenário, destacando-se a esteira com tons mais claros e vibrantes, o Sistema Brasileiro de Televisão (SBT) realizou uma alteração estilística. Essa mudança não ocorreu apenas no título - transformado em interrogativa direta composta, concomitantemente, por paronomásia e antítese, extrapolando a sonoridade e a lógica - e no formato, mas também no impacto cultural proposto pelo programa, que já se mantém no ar, na televisão aberta brasileira, há quase quatro anos.

\section{Objetivos e justificativa}

Na tentativa de discutir quais são os efeitos estilísticos responsáveis por preencher a narrativa de um quadro de namoro prestes a completar um quadriênio no ar - resistindo em audiência, enquanto outros já foram extintos -, questionou-se o que há de peculiar, em sentido comunicacional e cultural, no objeto em evidência. Ao selecionar como recorte a exibição do Rola ou enrola? em 15 de março de 2015, buscou-se, por meio de uma análise estilística do conjunto audiovisual, pautada na transição entre os estudos literários e televisivos, conhecer a construção de um produto televisual de cunho afetivo e seu suposto reflexo na sociedade telespectadora.

\section{Metodologia}

Analisar a estilística de um quadro de programa de auditório - que, acima de qualquer condição, pode ser entendido como texto confeccionado nas camadas verbal, sonora e visual - seria, portanto, unindo-se a Todorov $(1971 ; 2006)$ e a Lotman $(1978$; 1993), explorar as quatro esferas que cercam a narrativa: forma, construção, sonoridade e significação. A análise estilística, comumente restringida ao texto verbal, não é restrita a essa modalidade de linguagem, mas pode ser verificada em outras manifestações de expressão. 
Do ponto de vista das teorias linguísticas, conforme explica Bechara (2009, p. 618-619), “o estudo da Estilística abarca, semelhante à Gramática, todos os domínios do idioma". Para isso, avalia-se a obra em fonética ("procura indagar o emprego do valor expressivo dos sons"), morfologia ("sonda o uso expressivo das formas gramaticais"), sintaxe ("procura explicar o valor expressivo das construções") e semântica ("pesquisa a significação ocasional e expressiva de certas palavras").

Partindo desse esquema, costuma-se classificar tais categorias em harmonia, tropos, construção e pensamento, termos adotados por Guiraud (1970). Nilce Martins (2008) utiliza os termos "estilística do som", "estilística da palavra", "estilística da frase" e "estilística da enunciação". Monteiro (1991; 2005) os denomina metaplasmos, metataxes, metassememas e metalogismos. Suhamy (1994) sugere a divisão em seis grupos: tropos, repetição e amplificação, construção, retórica, elipses e pensamento. Para este trabalho, contudo, segue-se a nomenclatura atribuída por Henriques (2011): fonoestilística, morfoestilística, taxioestilística e semasioestilística.

Os estudos do estilo, aprofundando a temática, têm conquistado seu espaço na comunicação audiovisual, sobretudo em se tratando da conceituação para o cinema. Bordwell (2013, p. 17) considera o estilo "um uso sistemático e significante de técnicas da mídia cinema em um filme", mencionando entre essas técnicas: "mise-en-scène (encenação, iluminação, representação e ambientação), enquadramento, foco, controle de valores cromáticos e outros aspectos da cinematografia, da edição e do som". Sintetizando as ideias, torna-se possível considerar o estilo como "a textura das imagens e dos sons do filme" (BORDWELL, 2013, p. 17).

Tal concepção foi transposta para a televisão: a de que o estilo é a composição de encenação, movimento de câmera, edição, som e artes gráficas (BUTLER, 1986, p. 55). No Brasil, o estudo do estilo no audiovisual começou a ganhar força na segunda metade da década de 2000 devido às traduções da bibliografia bordwelliana, conforme posiciona Pucci Jr. (2014, p. 2). Muitas dessas pesquisas ainda são relacionadas ao cinema ou à ficção televisiva, com pouco enfoque nas narrativas em processo, como os programas populares.

Para uma análise estilística completa, portanto, acredita-se no estudo do conjunto: observam-se os aspectos que tendem à visualidade e à sonoridade, aliados aos fenômenos verbais de fala e escrita, também pertinentes ao produto audiovisual. Rocha (2016), com base em obras precedentes, sugere que a análise estilística seja composta por três partes: descrição, oferecendo uma desconstrução da narrativa; interpretação, visando investigar a função dos seus aspectos; e avaliação, propondo uma reflexão crítica acerca da obra.

Tendo em vista que este é um exercício inicial sobre o tema, ainda carente em se tratando de programas de auditório, demanda-se esforço na primeira dimensão: busca-se 
identificar quais os recursos estilísticos presentes, e comenta-se a contribuição que tais elementos oferecem ao produto televisivo. As menções às figuras de linguagem, portanto, são comuns, afinal elas são a base da estilística descritiva utilizada pela literatura; aqui, elas são apresentadas como propostas para criação de uma narrativa audiovisual.

\section{Análise estilística do Rola ou enrola?}

O Rola ou enrola? não se encontra registrado, no site do SBT, entre os quadros do programa Eliana. É possível localizar os seguintes quadros: Nó na língua, Fenômenos do YouTube, Beleza renovada, Sueli em sua casa, Rede da fama, Quer casar comigo?, Ciência em show, Familia pede socorro, Reencontro e Adóoogo. Nada, no entanto, faz referência ao semanal Rola ou enrola?, que ocupa cerca de 60 minutos de um programa de quatro horas.

$\mathrm{Na}$ seção destinada às inscrições, no entanto, há um espaço exclusivo para os que desejam participar do quadro. Outros quadros, também ausentes na página destinada aos demais, aparecem nessa listagem - são os casos de: Força do bem, Entrega pra você e Desafio pet. Ao lado do botão "inscrever-se", existe a seguinte definição, ipsis litteris: "Você acha que homem é capaz de tudo pra conquistar uma mulher? Vocês não viram nada!" (ELIANA, 2009-). Apenas nesse trecho, redigido aparentemente para atender ao nível coloquial de linguagem e se comunicar com o espectador/leitor de maneira informal, é possível detectar alguns recursos de estilo adotados pela produção do programa.

A presença do "você" propõe uma ligação íntima com o espectador/leitor. Faz-se uso, aqui, da função conativa de linguagem (MARTINS, 2008), que implica unir as duas pontas da linha midiática responsável pela comunicação entre os elementos - grupo televisivo e telespectador. Além disso, ao inserir um questionamento seguido de uma frase de indicação, leva-se a crer que a emissora deseja que o espectador/leitor aceite que ele também participa do processo de criação; que o canal desenvolve uma relação de alteridade, preocupando-se com a participação do outro, do telespectador que é convidado a deixar a passividade da recepção de lado e atuar como um cocriador do produto em questão.

Nota-se, ainda, que o "você" ganha um plural logo no início da segunda oração, o que pode configurar uma silepse de número, isto é, a mistura de singular e plural dentro da mesma expressão para se dirigir a um mesmo espectador/leitor. Talvez esse fenômeno tenha ocorrido com o propósito de ampliar o público a que o texto se destina: o enunciado se inicia com uma abordagem branda, fazendo referência ao indivíduo, mas se encerra em abrangência coletiva. Além disso, tem-se em mente que a silepse é uma figura que pode ser provocada pela polissemia, derivada da "ausência de relação biunívoca entre os sons e os sentidos" (TODOROV, 2006, p. 57), ou seja, deixa de existir uma relação única 
entre cada um dos elementos de dois conjuntos distintos. Com isso, torna-se viável refletir que, com a silepse, o "você" da primeira oração não necessita ser distinto do "vocês" da segunda oração, permitindo que ambos os termos possam ser considerados significantes de um mesmo referente - no caso, o espectador/leitor.

Outro recurso utilizado no texto, semelhante à silepse de número, é a metonímia do singular pelo plural. O termo "homem" aparece sem determinantes, enquanto o termo "mulher" é precedido de artigo indefinido feminino. Com isso, leva-se a crer que não se trata de um único homem, nem de um homem específico, e sim de um grupo de homens - o gênero masculino -, que tenta conquistar uma única mulher - indeterminada, embora quantificada - em um mesmo tempo, presente, atribuindo à metonímia o caráter de "combinação in praesentia" (LOTMAN, 1993, p. 27). Dessa forma, sugere-se que o poder de escolha da mulher, o direito de optar pelas alternativas masculinas que the são apresentadas, fica em evidência.

Há uma série de questionamentos, ainda nesse enunciado, que resultariam, somente eles, numa pesquisa acadêmica: qual teria sido o sentido aplicado ao adjetivo "capaz"? Haveria ambiguidade no verbo "conquistar"? Por que ter-se-ia optado pela utilização de "pra" em vez de "para"? Qual teria sido a intensão discursiva para negar uma negativa, na segunda oração do período? Existiria relação entre o "tudo" na primeira oração e o "nada" na segunda oração? E na dicotomia interrogativa/exclamativa? No entanto, visto que uma análise linguística desse porte, que tende a se inclinar para a hermenêutica, não é o foco deste trabalho, encerram-se aqui as reflexões acerca do texto verbal.

\section{Descrição do produto}

Às $18 \mathrm{~h} 06$ de 15 de março de 2015 entra no ar, durante o programa Eliana, pelo SBT, um episódio inédito do Rola ou enrola ? $^{1}$ (ELIANA, 2015). A data, por sua vez, foi marcante para a história brasileira contemporânea, visto que houve, em todas as regiões do país, aglomerados de manifestantes contra a corrupção e contra a gestão do Governo Federal de então (EBC, 2015). Devido a esse fato, o programa Eliana foi interrompido, algumas vezes, pelos plantões do SBT, desconfigurando trechos da atração - como o quadro Eliana visita, previamente anunciado, mas não exibido.

No quadro Rola ou enrola?, no entanto, acredita-se que não houve perdas significativas ou que viessem a comprometer as análises. Ao iniciar a diegese - ou seja, o mundo construído pela narrativa - com palmas da plateia, o que poderia representar que o quadro estaria sendo esperado e, portanto, seria muito bem-vindo, a apresentadora faz a

1 ELIANA (15 mar. 15) - Coringa gato atiça a mulherada no Rola Ou Enrola. Direção de Ariel Jacobowitz. São Paulo: SBT, 2015, 56 min., telev., son., color. Disponível em: <https://goo.gl/KpSEHg>. Acesso em: 17 mar. 2015. 
chamada inicial: "Minha gente, o negócio tá sério. Segundo o IBGE, existem no Brasil 5 milhões de mulheres a mais do que homens...". Sua fala é interrompida, neste ponto, por um "irra" emitido pela sonoplastia. No instante seguinte, ela continua: "ou seja, não tá fácil pra ninguém. Começa agora: Rola ou enrola?!” (ELIANA, 2015).

Apenas nessa introdução, é possível notar a presença de duas vozes, de dois discursos: um estatístico, pautado em números obtidos por pesquisas e índices geográficos; outro mais coloquial, com expressões-chavão e abreviações. A reação esperada para a informação, acima de tudo, é traduzida pela interjeição emitida pelo sonoplasta: "irra", neste caso, vem a ser um sinal de alerta para representar que a situação anda acirrada, disputada. Bordwell $(2008 ; 2013)$ comenta que, no cinema, o estilo é formado tendo por base três elementos: a movimentação e angulação de câmera; o que está representado na mise-en-scène; e a trilha sonora, que costuma se dividir em falas, diálogos, ruídos, efeitos de áudio, música e outros sonos. Transportando esse conceito para a televisão, e focando especificamente no terceiro elemento discutido por Bordwell - o trabalho com a trilha sonora -, percebe-se, no objeto analisado, como a sonoplastia tem forte relevância na composição da narrativa, complementando, sempre que possível, a trama que se vem construindo.

Após anunciar o nome do quadro, a voz da apresentadora dá espaço à vinheta inicial, momento em que a câmera registra a logomarca do quadro no chão do palco um círculo vermelho preenchido por um coração na parte de baixo e no qual está inscrito o nome do quadro, além de luzes em forma de estrela circulando em cima. Antes mesmo de a imagem da apresentadora voltar à cena, ela dá a ordem: "mulheres, podem entrar!". Existem estudos, como os de Rocco (1989), sobre o uso de uma gramática autoritária nos programas do SBT, sobretudo quando liderados por Silvio Santos. Visto que este não parece ter sido o propósito da apresentadora, optou-se por não aprofundar o assunto neste trabalho.

Ao som de will.i.am (featuring Mick Jagger \& Jennifer Lopez) $)^{2}$, entram as cinco participantes: Marcelle, Deisy, Camila, Carol e Kelly. Cada uma das garotas, já presentes em programas anteriores, sustenta uma personalidade peculiar: lasciva, intelectual, consumista, conservadora e liberal, respectivamente. Embora elas já sejam conhecidas do público e tragam uma plaquinha no peito informando seus nomes, a apresentadora os repete em voz alta, conforme elas vão aparecendo. A música eletrônica, de certa forma, traz um ar de festa, balada, fortalecendo a animação no palco. A plateia, em palmas ritmadas e gritos de "uh, uh, uh", corroboram o sentimento de alegria e descontração. Novamente,

2 will.i.am. T.H.E. Disponível em: < https://youtu.be/vjIwmJMqrco>. Acesso em: 15 mar. 2015. 
nota-se a presença da sonoplastia, dessa vez com o apoio da música, incluída com o propósito de afetar o espectador - de acordo com Bordwell (2008, p. 29), por meio do estilo "somos afetados, mas não percebemos".

A apresentadora desce do pedestal em que se encontra e se dirige ao meio do palco para conversar com as moças, indignada com o retorno delas - especialmente com o de Kelly, que, segundo a própria Eliana, havia escolhido um "bofe" (ipsis verbis) perfeito no programa anterior. Em seguida, a apresentadora chama o vídeo gravado com os pretendentes, que explicaram sua versão de por que o relacionamento não vingou. Como o pretendente de Deisy não aparece no vídeo, Eliana interroga a moça: "ele não quis sair contigo?". Deisy tenta se explicar, mas é atropelada pela afirmação de Eliana, que evita os circunlóquios: "ele não quis sair contigo". A plateia se expressa com "ih" e "ah", enquanto a sonoplastia dispara o jargão "toma, distraída!", seguida de risos eletrônicos.

Com feição de indignada, a apresentadora chama o videotape do encontro entre Kelly e o rapaz que a participante havia escolhido. Ambos foram passear no zoológico, onde o rapaz iria mostrar à moça o que ele denominou "pegada do macaco". Outros trocadilhos surgem ao longo do vídeo: "você tá de fralda? Bundão!"; "eles [os flamingos] têm a perna bem fininha, né? Parecem com as suas!"; "você acha o gato do mato mais bonito que o gato da cidade?". Volta a imagem do palco e a apresentadora conversa brevemente com Kelly antes de chamar o primeiro candidato. A constituição do humor, que ressurge em vários pontos da narrativa, é, segundo Zilles (2003), não só uma relação estabelecida com o cômico, o grotesco, o burlesco, o irônico, o sarcástico, mas que também diz respeito à excentricidade, à ludicidade - como se torna possível averiguar no programa analisado.

Apenas nessa parte, já é possível notar a intimidade que se estabelece entre narradora (Eliana) e personagens (participantes), bem como entre a narrativa criada e os possíveis leitores: o público (em casa) é convidado a participar da vida pessoal das garotas, podendo, sobretudo, palpitar, sendo suscetível ou não às reações da plateia, que, comunicando-se apenas por onomatopeias, consegue atuar como deuteragonista dessa narrativa, colaborando para realçar o comportamento que se espera do telespectador diante das situações. Rafael Martins (2016) destaca como as produções do SBT costumam privilegiar seu público, sempre colocando o povo à frente de seus protagonistas, criando a ilusão de que são os espectadores quem comandam a atração. $\mathrm{O}$ jogo audiovisual que torna umbilicadas iluminação e trilha musical demarca o contexto que o programa aparentemente pretende transmitir: arrumar namorado, por mais complexo que possa parecer, também pode ser divertido.

O primeiro candidato, então, entra na esteira. Chama-se José Alberto e é colombiano. Com uma máscara de Ricky Martin, o rapaz, que mal consegue se expressar em português e faz uma breve apresentação arriscando-se no portunhol, usa seus 60 segundos 
para dançar ao som de Living la vida loca. Rocha (2016) comenta sobre a impregnação de fenômenos comuns à cultura latina nos programas do SBT - emissora que, embora pertença à América Latina, está conceituada no antro brasileiro de se fazer televisão ${ }^{3}$. Muita palma ritmada; muito barulho de interjeições; muita luz piscando; plateia mexendo o corpo, em plano conjunto, apresentadora dançando ao lado do pedestal, em plano americano... O rapaz, no centro do palco, exibido em plano médio, torna-se um mero figurante na cena, que é composta principalmente pelo que está a seu redor; mesmo assim, ele é a estrela da vez até que o tempo se esgote.

Em contraponto, o gerador de caracteres (GC) estampa, com um trocadilho, a interrogativa: "será que alguém vai aceitar o convite para viver a 'vida loca'?". Novamente, o telespectador é convidado a participar do enredo, torcer para que o rapaz seja ou não escolhido por uma das garotas. Visto que é esperado que o candidato seja um anônimo, não acostumado a se portar diante da câmera, a apresentadora conversa com ele, brincando com sua atuação no palco, fazendo piadas, rindo e procurando entender mais sobre o seu perfil pessoal, familiar e profissional.

Sousa (2011) repara nesse tipo de comportamento no programa Roda a roda, também do SBT, em que Silvio Santos, na tentativa de aliviar a adrenalina dos concorrentes que estão, a maioria, pela primeira vez em rede nacional -, estabelece uma conexão paralela àquilo que estaria previsto no roteiro do programa. Outro fator mencionado aqui, também defendido por Sousa (2011) a respeito dos programas do Silvio Santos, é a relevância dada ao outro - no caso, o público telespectador. Este não é apenas um leitor passivo do texto midiático que se desenrola, mas convidado a acreditar que pode ajudar no desenvolvimento da história, o que lhe gera a ilusão de ser um coprodutor, um colaborador a distância do programa Eliana.

Notando que o candidato ainda está usando a máscara, Eliana lança uma indireta para a plateia, alegando que seria interessante que ele tirasse o acessório. A plateia, portanto, grita eufórica: "Tira! Tira! Tira!" - e deduz-se que o telespectador também estaria desejando isso. Com o rosto revelado e a conversa com a apresentadora encerrada, o candidato é colocado sob a pressão do interrogatório feito pelas participantes. Camila é a primeira a perguntar e deseja saber se ele "se identifica com o Ricky Martin em tudo". A sonoplastia se encarrega de inserir um gritinho já considerado um estilema estereotipado para caracterizar o homem gay. Ele responde que apenas dança como o cantor, e Deisy entra em um novo assunto: o fato de já ter morado na Colômbia por um ano e conhecer muitas coisas do país.

3 Lopes (2009), por exemplo, define o padrão da Rede Globo como representativo do que tende a se chamar de televisão brasileira, especialmente no que diz respeito à teledramaturgia; porém, isso pode se estender aos programas de entretenimento. 
Eliana a interrompe com o questionamento: “quem?", ao que Deisy responde: “eu”, e é replicada pelo trocadilho de Eliana: “quem... perguntou?!". A sonoplastia emite um som de soco, seguido de grito de dor, relincho e risada. Risos no palco, aplausos na plateia e, mais uma vez, o objetivo do programa é deixado de lado para dar espaço ao humor.

Retomando o foco, Eliana pede para as garotas mostrarem suas placas. Quatro optam por "Tô fora!", incluindo Deisy e Camila, que, a priori, mostraram-se interessadas. A única a mostrar "Eu quero" é Carol, que se manteve "quietinha, mas quer", nas palavras da apresentadora. A plateia, exibida novamente em plano conjunto, cantarola, em palmas ritmadas, "Vai, Carol!", colocando os ombros para a frente e retraindo-os, repetidas vezes, até que a moça se levante, cole um adesivo com seu nome no candidato e volte ao seu lugar. O rapaz escolhido se retira para a lateral do palco, onde há um pedestal com o nome das cinco participantes; ele se posiciona em cima do nome "Carolina".

Eliana chama o candidato seguinte e o processo se repete: exibição pessoal de um minuto, conversa com a apresentadora, interrogatório com as garotas, momento da escolhatudo feito com muito brilho, muito berro, muito riso, muito desvio de foco, muitos fatores determinantes de alto-astral bastante elevado. Os candidatos, por sua vez, exibem-se nos trajes mais amalucados imagináveis: Gabriel, por exemplo, aparece vestido de bebê (apenas de touca, babador, fralda e chinelos) e, além de falar com voz fina, imita trejeitos homossexuais. Após sua atuação, todavia, Eliana anuncia a presença do Curinga figura que será focalizada mais adiante -, com o qual conversa em vários momentos do programa. Com a chegada do terceiro candidato, contudo, há a inclusão de um outro personagem na narrativa.

Lucas é o terceiro candidato e chega vestido como mágico. Traz nas mãos uma cartola da qual tira presentes para as meninas: um gel redutor de gordura localizada para a Marcelle; um par de chinelos para a Deisy (chamando-a, equivocadamente, de Denise); um contrato de separação de bens para a Camila; um bilhete de spa day para a Carol dar de presente à mãe e deixá-los sozinhos; e um vale-rodízio para a Kelly, com direito a espeto de picanha e muita linguiça. O duplo sentido, aliás, presente em muitos momentos do quadro, é um fenômeno fundamental para a consolidação da comicidade. Ressalta-se que o isso constitui uma figura de estilo denominada "trocadilho", a qual consiste na "utilização de palavras, abusando do seu sentido ambíguo" (HERGESEL, 2013, p. 70).

Na conversa que Eliana estabelece com o rapaz, ela pergunta se ele também dança; em resposta, ele diz que é funkeiro e íntimo do sertanejo. Ao som de um funk, seguido de Macarena, ele se requebra no centro do palco, mas logo é interrompido por Eliana, que critica o remelexo. As participantes, em defesa do rapaz, alegam que o blazer está 
atrapalhando e o induzem a tirar a camisa. A plateia, novamente, grita eufórica: "Tira! Tira! Tira!". A sonoplastia complementa a cena com sirenes de bombeiro. Uma música sensual ganha espaço e Lucas faz charme para tirar a roupa; ao começar a desabotoar a camisa, no entanto, Eliana berra o bordão que já se consagrou no programa: "Chama o Bombeiro!", prezando pelo alongamento no último "o" e insinuando urgência, desespero. Aparece, então, o Bombeiro.

\section{Observações sobre o personagem Bombeiro}

O personagem Bombeiro é a representação da virilidade, o símbolo da masculinidade e do encanto aos olhos femininos. Quando a apresentadora grita o estilema "chama o Bombeiro!", as mulheres da plateia se ensandecem com o rapaz musculoso e fardado que entra com um extintor na mão e ao som de um funk, cuja letra se resume à repetição de: "chama o bombeiro! Tá com fogo na frente, fogo no bumbum"4. Ele brinca com as participantes, com o auditório e com a própria apresentadora, borrifando uma porção de pó químico nos presentes.

Não se trata de um profissional credenciado, que visa realmente ao combate de incêndios, mas de Brunno Camargo, modelo contratado unicamente para essa função. Embora ele componha o Rola ou enrola?, não é exclusivo desse quadro: às vezes, o Bombeiro também aparece no Rede da fama e em outros momentos em que a estética corporal de um indivíduo (normalmente do sexo masculino) acarreta ânimo intensivo nos corpos alheios (geralmente do sexo feminino). O Bombeiro é invocado na tentativa metafórica de "apagar o fogo" daquelas que estão exaltadas.

Fazendo um breve levantamento sobre a carreira artística de Brunno, descobre-se algumas curiosidades: o modelo, que foi vencedor do I Concurso Nacional de Strippers, também estampou a capa da $172^{\mathrm{a}}$ edição da revista G Magazine, voltada ao público homossexual masculino (A EDIÇÃO..., 2012). Além disso, o modelo ainda é garoto-propaganda da campanha Perturbe, por favor, da marca 269 Chilli Pepper Single Hotel (269 CHILLI..., 2014), estabelecimento equipado com saunas, piscinas e bar para atender apenas a clientes do sexo masculino - em sua notável maioria, que têm interesse sexual em outros homens.

Uma nova série de questionamentos surge neste ponto: como se desenvolve a metáfora do Bombeiro como personagem para enfeitar os momentos alvoroçados sexualmente? Existe uma conexão entre o ritmo da música que preenche a trilha sonora e a imagem que se desprende da cena? Qual teria sido o motivo da escolha de um ator/modelo previamente estigmatizado como símbolo sexual do público gay? Como a televisão colaborou para a alteração das (ou o incremento de novas) marcas estilísticas? De que

4 MC K9. Chama o bombeiro. Disponível em: <https://youtu.be/kzFtNB_5HU>. Acesso em: 15 mar. 2015. 
maneira se dá a transição, no audiovisual, entre os diferentes públicos? Entretanto, como esse não é propósito da pesquisa, encerram-se aqui as divagações acerca do personagem.

\section{Observações sobre o personagem Curinga}

O personagem do Bombeiro entra outras duas vezes no episódio do Rola ou enrola? analisado; uma delas é quase no final do programa, quando o Curinga é revelado. Inspirado na carta de baralho de mesmo nome, cuja função é atribuída de diferentes maneiras, dependendo do jogo, o Curinga é um personagem transformativo, visto que sua imagem se renova a cada programa. Trata-se de um candidato "extra", que fica posicionado durante todo o tempo de duração do quadro atrás de um biombo, respondendo às perguntas feitas por Eliana e pelas cinco participantes. Ninguém vê nada além de sua silhueta, sendo ele conhecido somente pela sua sombra, pela voz e pelas respostas que forneceu ao longo do episódio. Ao final do programa, quando os candidatos da esteira se esgotaram, a apresentadora pede para as participantes levantarem a placa, mostrando quem quer trocar o homem que já escolheu pelo Curinga.

No recorte analisado, o Curinga é focalizado nos dez minutos finais. A conversa, nesse momento, inicia-se com a pergunta de Eliana: "você tá a fim de namorar sério ou tá a fim só de ficar?", para a qual segue a resposta: "eu quero namorar sério. Cansei dessa vida de bagunça. Eu quero uma pessoa bacana". Outras perguntas são feitas sobre fidelidade, definição de personalidade e filosofia de vida, recebendo comentários - defensivos e agressivos - das cinco participantes. Ainda sem que elas tenham visto o rapaz, Eliana pede para que mostrem suas placas. Marcelle, Deisy e Camila exibem a frase "Eu quero", dispostas a trocar pelo Curinga o candidato que já tinham escolhido. A plateia grita em tom de surpresa, e Carol e Kelly são interrogadas sobre os motivos que as levaram a tomar a decisão de não querer trocar.

Após a justificativa das moças, Eliana convida o Curinga a se dirigir ao palco. Ao rasgar o tecido que envolve o biombo, a plateia berra em exaltação devido à beleza física do rapaz, que desfila ao som de Ne-Yo (featuring Juicy J) ${ }^{5}$. Seu nome é revelado: Diego. Como ele havia informado anteriormente que não admira garotas de pés feios, as três participantes que o escolheram são convidadas a mostrar seus pés. No final, Diego escolhe Marcelle, que comemora, levanta-se para colar o adesivo no rapaz e aproveita para beijá-lo, também com She knows como trilha sonora.

Diante do beijo de língua protagonizado pelo casal, a plateia grita, sirenes disparam, e Eliana, tentando esconder a cena com o próprio corpo, chama novamente o

5 Ne-Yo. She knows. Disponível em: < https://youtu.be/9-KiYo4BwVI>. Acesso em 22 mar. 2015. 
Bombeiro. A música de Ne-Yo é interrompida e o funk do MC K9 ocupa o espaço. O Bombeiro entra pela esteira, dispara o extintor em cima de Marcelle e do Curinga e corre pelo palco borrifando pó químico, enquanto o auditório grita, as luzes balançam, a sonoplastia emite algumas interjeições, a câmera tenta registrar o Bombeiro e o Curinga intercaladamente, e a amálgama de elementos componentes surgidos ao longo da narrativa consolida o momento, que, por isso, pode ser compreendido como clímax.

Por fim, ao som de will.i.am, Eliana se despede dos casais formados: Marcelle e Diego (Curinga), Deisy e Bruno, Camila e Leonardo, Carol e Lucas, Kelly e Edson. Um a um, eles sobem na esteira, que se movimenta levando-os para fora de cena. Eliana então informa: "esse foi o nosso Rola ou enrola?!", evidenciando o pronome "nosso" e incluindo o público como parte do processo. Em seguida faz os agradecimentos: "obrigada pela sua audiência. Obrigada pelo seu carinho. Fica com Deus. Beijo da família e até semana que vem". Entra a música temática ${ }^{6}$ do programa e Eliana se despede: "tchau, gente. Valeu!". A câmera se abre em posicionamento contra-plongée e registra, em plano geral, Eliana, o cenário como um todo e parte dos profissionais responsáveis pela execução do programa.

\section{Apontamentos finais}

Rola ou enrola? é um produto televisivo cujo estilo demonstra forças para resistir a uma época em que programas de namoro na cultura audiovisual brasileira estão ficando desgastados. Os mais recentes, por exemplo, Quem quer casar com meu filho? (Rede Bandeirantes), Me leva contigo (Rede Record) e Papito in love (MTV), foram descontinuados por suas respectivas emissoras. Já os quadros similares, Namoro com... (Eliana), Se virar, tem que beijar (Domingo Legal) e Eu vou beijar você! (Silvio Santos) são veiculados pelo próprio SBT, de forma esporádica, geralmente em período de hiato do Rola ou enrola? ou quando a audiência da emissora parece clamar por mais entretenimento do gênero.

Nesta análise, o que ficou constatado é que o estilo do Rola ou enrola? se consolida não somente pelo conteúdo, propondo algo inédito a cada semana - causando a ansiedade em saber quem serão os candidatos e como eles se exibirão, por exemplo, além dos trocadilhos inventados espontaneamente pelas participantes e pela apresentadora -, como também pela forma: é uma obra televisiva que parece reconhecer, nas técnicas de iluminação e de sonoplastia e no envolvimento com a plateia, sua devida importância para confecção do todo. Nota-se, portanto, que a edição do Rola ou enrola? denota uma participação coletiva que vai além dos elementos visíveis em cena.

6 Eliana. Abertura. Disponível em: <https://youtu.be/yvVGhffJHTE>. Acesso em: 22 mar. 2015. 
A sonoplastia, como supramencionado, tem um estilo audaz que colabora na condução da narrativa. Desde as pequenas unidades sonoras - como gritos, choros, menções a socos e imitações de flatulência - até a trilha musical - uma mescla que vai do sertanejo ao funk, do pop internacional ao folk latino -, é a comunicação sonora que ajuda a contextualizar as situações que se desenvolvem. A iluminação, por sua vez, tem peso equivalente, uma vez que é a irradiação dos brilhos e das cores claras e movediças/piscantes que personaliza o sentimento do programa. Essas são a maior contribuição estilística do Rola ou enrola?: a sensibilidade não se manifesta, de modo exclusivo, por meio de palavras, e sim, principalmente, pelas luzes e pelo som. Esses elementos traduzem a animação, a euforia, o ritmo acelerado e alto-astral do quadro, concatenando-se com o slogan "a TV mais feliz do Brasil", adotado pelo SBT desde 2009.

A plateia também tem sua grande parcela de contribuição para a estilística do quadro e consequente composição da narrativa, uma vez que ela é o representante do telespectador no palco. Mesmo que a comunicação do auditório fique limitada a onomatopeias e curtas frases de efeito, é esse coletivo que se torna responsável por elevar o ânimo da narrativa, preenchendo possíveis lacunas do audiovisual e sugerindo despertar, nas pessoas em casa, a vontade de dialogar com o enredo. A alteridade, nesse caso, é evidente, pois propõe ao telespectador uma pseudossensação de cooperatividade no desenvolvimento do quadro, como se nada do que estivesse ali pudesse acontecer sem o apoio e as reações de quem está na frente da tela - o que não é verdade, visto que o programa sequer é ao vivo e não permite contato direto com o público (via telefone, e-mail, redes sociais ou outra forma de comunicação).

A partir de 29 de março de 2015, após a coleta dos dados para esta pesquisa, o SBT decidiu exibir a atração ao vivo, interagindo com o público pelo Twitter (por intermédio da hashtag \#ElianaAoVivo e com mediação de Rodrigo Banguela, jurado do quadro Famosos da internet) e com os passantes no Shopping Aricanduva (em São Paulo, com mediação da personagem Narcisa, também jurada do Famosos da internet). Desde 5 de abril de 2015, no entanto, o quadro Rola ou enrola? não foi mais exibido. A justificativa, via perfil não oficializado do quadro no Twitter (twitter.com/RolaOuEnrolaSBT), é que a produção do programa estaria estudando maneiras de adaptar o quadro para atender às expectativas da modalidade ao vivo. Em 29 de outubro de 2016, entretanto, o programa voltou a ser previamente gravado; mesmo assim, o Rola ou enrola? retornou à pauta apenas em 2017, entrando em novo hiato logo após algumas semanas.

A não linearidade também deve ser compreendida como um grande achado. Por mais que a forma, levando em consideração os elementos estruturais, seja semelhante a cada passagem (a cada atuação de candidato, por exemplo), inexiste uma sintaxe fixa, já 
que diversos desvios de foco e diálogos não roteirizados ocorrem a todo instante e, de certa forma, tornam a harmonia mais light, sem a característica engessada de programas fielmente roteirizados e que não devem, em nenhum momento, sair do controle de seus produtores. O resultado, sobretudo no recorte analisado, pode ser notado na audiência: 8,5 pontos em São Paulo durante o programa Eliana, acima da média-dia do SBT, que era de 7,2 (CONFIRA..., 2015).

Para encerrar este pensamento, cabe dizer que, se fosse necessário resumir em uma máxima a estratégia estilística que consagra o Rola ou enrola?, esse termo seria "gramaticalidade do espontâneo". Tal como o telespectador não tem um itinerário que se deve seguir para caminhar pelos veios do programa (embora tenha uma ideia inicial sobre o que esperar do quadro), a produção acaba tendo uma projeção exata do que ocorrerá somente após o término das gravações, visto que o desenvolvimento é passível de surpresas que resultam um desfecho rolante. Essa simulação de naturalidade, corroborada pelos editores, é que talvez tenda a atrair o público.

\section{Referências}

269 CHILLI Pepper Single Hotel. Perturbe, por favor. 2014. Disponível em: <https://goo.gl/U74SFv>. Acesso em: 15 mar. 2015.

A EDIÇÃO 172 da revista G já está nas bancas. Sertânia Vip, Sertânia, 2012. Disponível em: $<$ https://goo.gl/1vwZPv>. Acesso em: 15 mar. 2015.

BALLY, C. Traité de stylistique française. Paris: Klincksieck, 1909.

BECHARA, E. Moderna gramática portuguesa. 37. ed. Rio de Janeiro: Nova Fronteira, 2009.

BORDWELL, D. Figuras traçadas na luz: a encenação no cinema. Tradução Maria Luiza Machado Jatobá. Campinas: Papirus, 2008. Sobre a história do estilo cinematográfico. Campinas: Unicamp, 2013.

BUTLER, J. G. Notes on the soap opera apparatus: televisual style and "As the World Turns". Cinema Journal, Los Angeles, v. 25, n. 3, p. 53-70, 1986.

Television style. New York: Routledge, 2010.

CONFIRA os consolidados de domingo (15/03/2015). Central Tudo sobre TV, [S.1.], 16 mar. 2015. Disponível em: <https://goo.gl/9C7Npo>. Acesso em: 7 abr. 2018.

EBC - EMPRESA BRASIL DE COMUNICAÇÃO. Protestos contra a corrupção e o governo ocorreram em todas as regiões do Brasil. 2015. Disponível em: < https://goo.gl/m4Rzus>. Acesso em: 22 mar. 2015.

ELIANA. Direção de Ariel Jacobowitz. São Paulo: SBT, semanal, 240 min., telev., son., color. 2009-. Disponível em: <https://goo.gl/MvzcgN>. Acesso em: 13 mar. 2015. 
ELIANA estreia o divertido quadro "Rola ou Enrola" neste domingo. Portal do SBT, São Paulo, 28 out. 2011. Disponível em: <https://goo.gl/JEcb7o >. Acesso em: 13 mar. 2015.

ENDEMOL Brasil. Conveyor Belt of Love: o romance rola solto durante o programa. Reality/game show. 2015. Disponível em: <https://goo.gl/S91sBr>. Acesso em: 13 mar. 2015.

FERNANDES, A. C. Namoro e familia na televisão: análise do programa de auditório "Em Nome do Amor". Dissertação (Mestrado em Sociologia) - Faculdade de Filosofia, Letras e Ciências Humanas da Universidade de São Paulo. São Paulo: USP, 2002.

FRANÇA, V. Narrativas televisivas: programas populares na TV. Belo Horizonte: Autêntica, 2006.

GALVÃO, L. M. N. M. R.; Duca, D. C. A. C. Modernização em programas televisivos de relacionamento e o comportamento juvenil na perspectiva do comportamento consumidor. Mercatus Digital, Recife, n. 1, p. 83-96, 2010.

GUIRAUD, P. A estilística. São Paulo: Mestre Jou, 1970.

HENRIQUES, C. C. Estilística e discurso: estudos produtivos sobre texto e expressividade. Rio de Janeiro: Elsevier, 2011.

HERGESEL, J. P. Estilística cibernética. Guaratinguetá: Penalux, 2013.

LOPES, M. I. V. Telenovela como recurso comunicativo. Matrizes, São Paulo, v. 3, n. 1, p. 21-47, 2009.

LOTMAN, I. M. A estrutura do texto artístico. Lisboa: Estampa, 1978. La retórica. Escritos: Revista del Centro de Ciencias del Lenguaje, Puebla, México, n. 9, p. 21-46, 1993.

MARTINS, N. S. Introdução à estilística: a expressividade na língua portuguesa. 4. ed. São Paulo: Edusp, 2008.

MARTINS, R. B. F. As mediações da interação do SBT com a audiência. Revista Mediação, Belo Horizonte, v. 18 , n. 22 , p. $67-83,2016$.

MONTEIRO, J. L. A estilística. São Paulo: Ática, 1991.

MONTEIRO, J. L. A estilística: manual de análise e criação do estilo literário. Petrópolis: Vozes, 2005.

PUCCI JR., R. L. Sobre a história do estilo cinematográfico. REBECA: Revista Brasileira de Estudos de Cinema e Audiovisual, São Paulo, v. 3, n. 1, p. 1-6, 2014. Disponível em: <http://goo.gl/KmC37C>. Acesso em: 1 fev. 2017.

ROCCO, M. T. F. A linguagem autoritária. São Paulo: Brasiliense, 1989.

ROCHA, S. M. Estilo televisivo - e sua pertinência para a TV como prática cultural. Florianópolis: Insular, 2016.

SOARES, R. Fica comigo: youth and love/sexual pedagogies on MTV. Educação em Revista, Belo Horizonte, n. 46, p. 311-335, 2007.

SILVA, A. A. et al. A descartabilidade dos relacionamentos humanos em programas televisivos: Uma análise crítica dos quadros de namoro na TV. In: CONGRESSO BRASILEIRO DE CIÊNCIAS DA COMUNICAÇÃO, 35., 2012, Fortaleza. Anais.... Fortaleza: Intercom, 2012.

SOUSA, S. M. Silvio Santos vem aí: programas de auditório do SBT numa perspectiva semiótica. Niterói: Editora da UFF, 2011.

$130) \frac{\text { Comunicação \& Inovação, PPGCOM/USCS }}{\text { v. 19, n. 39 (114-131) jan-abril } 2018}$ 
SUHAMY, H. As figuras de estilo. Porto: Rés, 1994.

TODOROV, T. As categorias da narrativa literária. In: BARTHES, R. et al. Análise estrutural da narrativa. Petrópolis: Vozes, 1971. p. 209-254.

. Linguagem e literatura. In: As estruturas narrativas. Tradução Leyla Perrone-Moisés. São Paulo: Perspectiva, 2006. p. 53-64.

ZILLES, U. O significado do humor. FAMECOS: mídia, cultura e tecnologia, Porto Alegre, v. 1, n. 22, p. 93-89, 2003. 